\title{
Fuel Oil from Municipal Plastic Waste through Pyrolysis with and without Natural Zeolite as Catalysts
}

\author{
Suhartono $^{1, *}$, Priyono Kusumo ${ }^{2}$, Ate Romli $^{1}$, M. Iqbal Aulia ${ }^{1}$, and Egi Muhamad Yanuar ${ }^{1}$ \\ ${ }^{1}$ Department of Chemical Engineering, Universitas Jenderal Achmad Yani, Cimahi 40533-Indonesia \\ ${ }^{2}$ Department of Chemical Engineering, Universitas 17 Agustus 1945, Semarang 50233-Indonesia
}

\begin{abstract}
The main purpose of this work was the possibility to process the plastic waste into an alternative fuel oil through pyrolysis. This pyrolytic fuel can be utilized as an alternative fuel for cookstoves as a liquid petroleum gas (LPG)/kerosene substitute for the household. The pyrolysis was conducted in a design of a simple, inexpensive and easy to operate semi-batch reactors that be applied definitely in urban and rural communities. Two type of plastic wastes were pyrolyzed up to $480{ }^{\circ} \mathrm{C}$ with and without natural zeolite as catalyst. The higher fuel yield (\%) was obtained when using zeolite in the process. The amount of $1000 \mathrm{~g}$ of two plastics waste type with natural zeolite yielded $650 \mathrm{~mL}(65 \% \mathrm{vol} / \mathrm{w})$ and $550 \mathrm{~mL}(55 \% \mathrm{vol} / \mathrm{w})$, respectively. The density of fuel oil product from $0.700 \mathrm{~kg} / \mathrm{m}^{3}$ to $0.710 \mathrm{~kg} / \mathrm{m}^{3}$, the fuel oil kinematic viscosity in the range of $1.07 \mathrm{cSt}$ to $1.14 \mathrm{cSt}$, and the heating value of $38 \mathrm{MJ} / \mathrm{kg}$ were obtained. The physical properties and the results of Fourier-transform infrared spectroscopy (FT-IR functional groups of this fuel oil were relatively close to that of conventional kerosene fuels. The operational cost of pyrolysis is about IDR $12,300 /$ liters of fuel oil.
\end{abstract}

Keywords: HDPE; LDPE; pyrolysis; catalyst; zeolite; plastic waste.

\section{1 introduction}

In Cimahi City, West Java, Indonesia, over 310.51 tonnes $\left(1523 \mathrm{~m}^{3} /\right.$ day $)$ of municipal wastes are produced each day and tends to increase due to an increase in population. Around $15 \%$ of this city's waste is the plastic waste with various types and characteristics. Most of the plastic waste is a type of polyethylene (PE) plastic. About 7.7\% of plastic waste is recycled plastic, while about $6 \%$ of plastic waste is plastic that is not recycled [1]. Grocery bag is one example of waste plastic types of polyethylene that is not recycled. Broken plastic utensils, used containers, packaging plastics, used toothbrush plastics are also abundantly present in municipal solid waste (MSW) generated from the household. Generally, these plastics are the type of polypropylene (PP), low-density polyethylene (LDPE) and high-density polyethylene (HDPE). This plastic waste is a potential of renewable resources for fuel oil production due to the abundantly and the increasing availability of the plastic waste stream around the local communities. The high calorific value of fuel oil is one of the most plastic waste options as a resource for fuel production. Plastic wastes can be converted to fuel oil via a thermal process. Fuel oil from plastic waste through pyrolysis is a more attractive process because of its advantage in the application. The fuel oil can be directly used in vehicles or combustion for the heat utilization. Direct combustion (incineration) and gasification are presumed less suitable as thermal processes of plastic waste with respect to toxic gases produced and high production costs. The only suitable for thermal process is degradation of hydrocarbon polymer of plastic waste into various smaller molecular weight fragments through pyrolysis.

Pyrolysis is the thermal decomposition of organic compounds in plastic waste at $350{ }^{\circ} \mathrm{C}-550{ }^{\circ} \mathrm{C}$ in the absence of air/oxygen [2-4]. Condensable gases (fuel oil) will be produced due to the break down the long chain hydrocarbon of plastic into smaller molecules under the pyrolysis conditions. The quantity and characteristics of the fuel oil produced depend on reactor configuration, plastic type, pressure/temperature, heating rate, etc [2]. There have been several studies in the literature reporting on pyrolysis of waste plastic to fuel oil related to its several techniques and socio-economic advantages [511]. The various types of pyrolysis reactors, such as batch and semi-batch reactors, fixed and fluidized bed reactor etc were used in the studies. Batch and semi-batch pyrolysis reactor consist of a cylinder for feeding charged plastics is the most widely used type because its design is easy and simple. However, currently, there have been no reports with respect to its real commercial application in urban or rural communities. The certain limitation in thermal pyrolysis, where the process is temperaturedependent. Commonly, the disadvantages of early pyrolysis technique are the use of electricity and liquid petroleum gas (LPG) for its heating systems. A very wide product range and high temperatures required are some major drawbacks of plastic waste pyrolysis using the batch or semi-batch reactor [11]. Low-conductivity

* Corresponding author: suhartono@lecture.unjani.ac.id 
plastic waste and high viscosity-produced fuel oil is a consideration parameter for pyrolysis reactor design. Therefore, this study is directed to develop a pyrolysis process with a heating system using biomass waste as a heat source. The first objective of this work is the study of the possibility to convert plastic waste into fuel oil using a simple, cheap and easy-to-operate semi-batch pyrolysis reactor. This process is expected to be implemented actually in urban or rural communities.

The aim of this work is the conversion of LDPE and HDPE plastic wastes into oil that could be utilized as an alternative fuel for household and vehicle. The pyrolysis process was performed in the presence and absence of natural zeolite catalyst using a semi-batch reactor. The paper report about the technical feasibility of the pyrolysis process, oil yield level, the production cost as well as its effect on the local economy. The experiments were conducted on semi-bath system reactor consist of pyrolysis vessel and a small catalytic reformer. Natural zeolite catalysts are selected with considerations that can be found easily in many local places and difficulty in recovery after use when using commercial catalysts [11].

\section{The material and method}

\subsection{Thermal pyrolysis}

A small-scale pyrolysis semi-batch reactor design was used for thermal degradation of plastic waste into liquid fuel oil. A semi-batch reactor with $20 \mathrm{~L}$ volume has a height of $40 \mathrm{~cm}$ with $25 \mathrm{~cm}$ diameter (Figure 1) was designed and constructed using mild steel sheet from inexpensive waste local material. The reactor was also connected with a small catalytic reformer vessel with a volume of about $1.5 \mathrm{~L}$. The reactor was equipped with temperature and pressure measurement system. The reactor was operated by a closed system in the absence of air $\left(\mathrm{O}_{2}\right)$. The thermocouple wire in the inside thermowell was placed right on the plastic waste pyrolysis zone in the reactor. All degradation experiments of plastic waste were carried out in both as thermal catalytic or without catalytic pyrolysis.

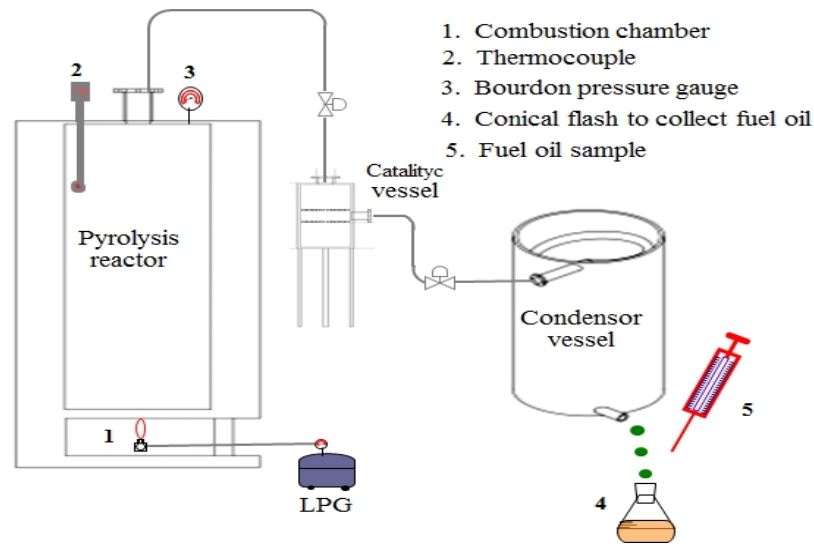

Fig. 1. Schematic representation of the semi-batch pyrolysis setup

The natural zeolite comes from Sukabumi, West Java, Indonesia and purchased from the local market. This natural zeolite catalyst was crushed to a size of about 10 $\mathrm{mm}$ and used in the catalytic vessel (catalytic reforming) without any further surface modification or activation [10]. A total of about $1000 \mathrm{~g}$ of natural zeolite catalyst was used for the reforming process (decrease the heavy oil fraction $\left(>\mathrm{C}_{20}\right)[11]$ of each experiment.

To carry out the pyrolysis, two type of HDPE and LDPE waste plastics were used individually as feedstock. These plastic waste samples were collected locally from household waste (municipal solid waste) as plastic bags, soft drink bottles, water bottles, juices cups, shampoo bottles etc. The sheet of clear plastic bags, sachet water bag, cosmetic bottles, lubricant bottles and soft drink bottles of polyethylene plastics were cut into small pieces. A certain weight of 1000 gram of waste plastic (LDPE or HDPE) was inserted into a closed pyrolysis reactor. Heat to pyrolysis reactor was supplied from the thermal of liquid petroleum gas (LPG) or corncob (biomass) combustion. In each experiment, the temperature of the pyrolysis reactor could reach up to $480{ }^{\circ} \mathrm{C}$, whereas the temperature of the gaseous products was the catalytic vessel condition without further heating. The vapor products of plastic waste pyrolysis were condensed using a water-cooled condenser. The condensable gaseous products (fuel oil) was collected at each operating time of $15 \mathrm{~min}$ and $20 \mathrm{~min}$. The total of fuel oil was collected in a conical flask for $280 \mathrm{~min}$.

Experiments using similar conditions but in the absence of natural zeolite catalyst on reforming vessel were also carried out for comparison. The yield of the fuel oil pyrolytic product was calculated by using the following equation:

$$
\text { Yield }(\%)=\frac{\text { volume of fuel oil }(\mathrm{mL})}{\text { Weight of plastic waste }(\mathrm{g})} \times 100 \%
$$

\subsection{Fuel oil product characterization}

The yield of fuel oil product was measured as the volume of the collected liquid compared to the initial amount of the pyrolytic plastic waste feed. The evaluated physical properties of fuel oil consisted of density and viscosity. The fuel oil density was measured gravimetrically at $30^{\circ} \mathrm{C}$ using volumetric glassware according to ASTM D1298 methods and by using a hydrometer (ASTM D-1298) [12]. The fuel was put in $25 \mathrm{~mL}$ pycnometer and weighed on a digital mass balance. The below equation was used to calculate the fuel oil density:

$$
\rho_{L}=\frac{\left(r_{B L}-m_{B}\right)}{V_{L}}
$$

Where $\rho_{\mathrm{L}}$ is the density of the liquid $\left(\mathrm{g} / \mathrm{cm}^{3}\right) ; \mathrm{m}_{\mathrm{BL}}$, the mass of bottle and liquid $(\mathrm{g}) ; \mathrm{m}_{\mathrm{B}}$, the mass of bottle only and $V_{L}$ is the volume of the liquid $\left(\mathrm{cm}^{3}\right)$. The viscosity of the fuel oil was measured by utilizing the Cannon-Fenske type 200 viscometer as suggested by ASTM D445. The fuel oil viscosity is calculated by the following equation [13]:

$$
v=t \cdot c_{0}(T)
$$


$v$ is the kinematic viscosity (centistokes, $\mathrm{cSt}\left(\mathrm{mm}^{2} / \mathrm{s}\right)$ ) $\mathrm{t}$ the flow time (seconds) and $\mathrm{c}_{0}(\mathrm{~T})$ the viscometer constant. Meanwhile, the calorific value of fuel oil can be calculated using a formula that correlates with the density of the fuel oil [12]. However, in this work, the calorific value of fuel oil as higher heating value (HHV) in $\mathrm{MJ} / \mathrm{kg}$ was estimated based on kinematic viscosity, $v$ by using equation (4) [13]:

$$
H H V=0.0137 v_{f}+38.053
$$

This equation used because it is more accurate, easier, faster, less costly and has been widely used to determine the density of various oils [14-16]. The contents of the aromatic hydrocarbon group compounds of this plastic waste pyrolysis oil were analyzed by using the Fouriertransform infrared spectroscopy (FT-IR) spectrum. The economic viability of the pyrolysis process was also calculated on the basis of LPG fuel consumption and the selling price of commercial fuel oil.

\section{Results and discussions}

\subsection{Properties of fuel oil product}

Density is one of the important properties of a fuel oil. The higher density of fuel oil will be less on fuel consumption and vice versa. Too low or too high density of fuel oil is not desirable due to some reasons in its applications. High fuel oil viscosity will cause incomplete combustion and lead to the formation of carbon deposits in the combustion vessel or burner. High fuel viscosity also affects the difficulty of ignition and pumping. In addition, the high viscosity will greatly affect the atomization and vaporization of fuel, which in turn impacts on fuel consumption.

Table 1. Physical fuel oil properties

\begin{tabular}{|l|c|c|c|}
\hline \multirow{2}{*}{ Feedstock } & \multicolumn{3}{|c|}{ Parameters } \\
\cline { 2 - 4 } & $\begin{array}{c}\text { Density, } \\
\mathrm{kg} / \mathrm{m}^{3}\left(25^{\circ} \mathrm{C}\right)\end{array}$ & $\begin{array}{c}\text { Viscosity, cSt } \\
\left(30^{\circ} \mathrm{C}\right)\end{array}$ & $\begin{array}{c}\text { Heating } \\
\text { value, } \mathrm{MJ} / \mathrm{kg}\end{array}$ \\
\hline HDPE (with catalyst) & 0.705 & 1.10 & 37.990 \\
\hline HDPE (without catalyst) & 0.710 & 1.14 & 37.991 \\
\hline LDPE (with catalyst) & 0.700 & 1.07 & 37.989 \\
\hline LDPE (without catalyst) & 0.702 & 1.14 & 37.992 \\
\hline Fuel type [12], [17-19] & & & \\
\hline Kerosene [19] & $0.780-0.810$ & $0.377-4.123$ & $37.96-38.11$ \\
\hline Gasoline & 0.780 & 1.17 & 42.50 \\
\hline Diesel oil & 0.807 & $1.9-4.1$ & 43.30 \\
\hline
\end{tabular}

The pyrolysis of waste plastic with and without natural zeolite catalyst resulted in lowering of density of fuel oil product from $0.700 \mathrm{~kg} / \mathrm{m}^{3}$ to $0.710 \mathrm{~kg} / \mathrm{m}^{3}$ (Table 1) is close to the density of kerosene. So the conventional fuel such as kerosene oil may be replaced by plastic wastes pyrolysis oil. Table 1 also depicted that the fuel oil produced from the pyrolysis process followed by thermal degradation with natural zeolite catalyst has a little bit lower viscosity than that produced from the pyrolysis without a catalyst. The fuel oil kinematic viscosity was in the range of $1.07 \mathrm{cSt}$ to $1.14 \mathrm{cSt}$. This may be due to secondary degradation reactions that facilitate by natural zeolite catalysts. The fuel oil recovered had large amounts of lighter hydrocarbons fraction (lower molecular weight hydrocarbon) resulted in lowering of viscosity and boiling temperature of pyrolysis fuel oil products [20]. The viscosity of plastic waste pyrolysis fuel oil obtained was comparably higher than diesel and in the range of kerosene. These values of density and viscosity are in the range of diesel oil, gasoline oil, and kerosene oil values referring to the results of previous researchers $[5,9,11$, $12,19,21]$. The viscosity parameters of this fuel oil will have an effect on the utilization.

The heating value is also one of the important properties in which its efficiency is assessed in its applications. The heating value is defined as the energy given out when the amount of fuel is combusted with sufficient air completely. The higher the energy content of the fuel, the higher the heating value of a fuel. The less fuel quantity is needed to achieve the required performance efficiency [21]. There is no significant difference between the higher heating values of fuel oil produced from both pyrolysis with and without natural zeolite catalyst. The heating values of pyrolysis oils show values that are not much different from other commercial oil. Both heating values (HHV) of HDPE and LDPE pyrolysis oils were about $39 \mathrm{MJ} / \mathrm{kg}$. Similarly, the average HHV of liquid oil produced by Rehan et al. (2016) was found to be $39.3 \mathrm{MJ} / \mathrm{kg}, 41.6 \mathrm{MJ} / \mathrm{kg}, 41.7 \mathrm{MJ} / \mathrm{kg}$ and 40.6 $\mathrm{MJ} / \mathrm{kg}$ respectively [21] obtained from thermal and natural zeolites and synthetic zeolites catalytic pyrolysis of plastic. Das and Tiwari (2018) carry out the conversion of plastic waste from household waste by low temperature $\left(300{ }^{\circ} \mathrm{C}\right.$ to $\left.400{ }^{\circ} \mathrm{C}\right)$ into plastic derived oil (PDO) with estimated high heating values of $46 \mathrm{MJ} / \mathrm{kg}$ [5]. The HHV value of this experimental fuel oil is still within the range of heating values of fuel oil from plastic pyrolysis results in general $[5,9,11,12,21]$.

The density, viscosity, and heating value are the important properties of fuel oil. The product fuels oil might be in the range of gasoline and kerosene. The experiment resulted in the physical fuel oil properties to be so close to that of kerosene $\left(C_{4}\right.$ to $\left.C_{16}\right)$ [19]. The produced liquid fuel oils are suitable for household heating applications but it less suitable as a transportation fuel due to its high of heavy hydrocarbon content. This fuel oil has to be upgraded to gasoline range hydrocarbons $\left(\mathrm{C}_{4}-\mathrm{C}_{12}\right)[18,19]$. These fuel oil physical properties affect the degree of initial preheating, atomization and vaporization which ultimately impact on fuel consumption and emissions. The main constraints of combustion fuel, incomplete combustion and the formation of deposits on the burner due to the properties of this fuel oil. Much fuel oil consumption will be needed on low density, low viscosity combined with the lowenergy content of fuel oil. However, more detailed studies should be undertaken to ensure further utilization of oils such as for household energy needs.

\subsection{Fuel oil product yield}

Polyethylene plastic wastes that have been cut into small pieces were and weighed with a certain weight of $1000 \mathrm{~g}$ were used in the experiment. The plastic wastes of LDPE 
or HDPE into a closed pyrolysis reactor individually. The operating temperature was in the range of $300{ }^{\circ} \mathrm{C}-550{ }^{\circ} \mathrm{C}$. The catalytic vessel was charged with approximately 500 $\mathrm{g}$ of natural zeolite catalyst to further degrade of plastic waste without additional heat. The products in the form of liquid fuel oil were accommodated in a measuring conical flask. The pyrolysis process is stopped if the oil does not drip again.

Time and temperature are very important factors, the temperature will affect the yield of fuel oil products. Therefore the increasing temperature during the pyrolysis has to be observed. The pyrolysis temperatures were recorded when the first dropped of liquid fuel oil begin to drip at the temperature of about $300{ }^{\circ} \mathrm{C}$. This means, in the case of a semi-batch process, plastic waste pyrolysis can be carried out at lower temperatures $\left(300^{\circ} \mathrm{C}-350{ }^{\circ} \mathrm{C}\right)$ than at the final stage of this process higher than $450{ }^{\circ} \mathrm{C}$. Although, pyrolysis at low temperatures has a lower rate of fuel oil production of about $3 \mathrm{~mL} / \mathrm{min}$ rather than at higher temperatures of about $7.5 \mathrm{~mL} / \mathrm{min}$. In this case, higher fuel oil product was obtained when the semi-batch pyrolytic process tends to the end.

It was found that the product yields increased with the increment in pyrolysis temperature at each operating time of 20 minutes for all type of plastic waste. In this work, the second stage of thermal degradation of plastic waste oil product was carried out using natural zeolite catalyst of about $10 \mathrm{~mm}$ in size without activation due to its costly and regeneration of the catalyst is a difficult task. A catalyst size of less than $10 \mathrm{~mm}$ leads to blockage of the catalyst vessel by tar in the first test. Therefore, a catalyst size of $10 \mathrm{~mm}$ was used in further experiments.



Fig. 2. Temperature profile and fuel oil yield

The amount of fuel oil product obtained for the second stage thermal degradation for plastic wastes with and without natural zeolite catalyst. Pyrolysis using a natural zeolite catalyst produced more fuel oil than that without a catalyst, as depicted in Figure 2. The effect of natural zeolite catalyst on product yield gave the significant improvement in increasing of reactor temperature. The long enough operation time into a pyrolysis temperature interval let to complete the degradation of long molecules of plastic compounds to smaller molecules of hydrocarbons $\left(<\mathrm{C}_{16}\right)$ [11]. The experimental resulted show that the influence of temperature increment is evident. There was an increase in the amount of oil produced that occurs at each operating temperature every 20 minutes. The higher the temperature and the longer the heating time the resulting fuel oil yield will be more and more.

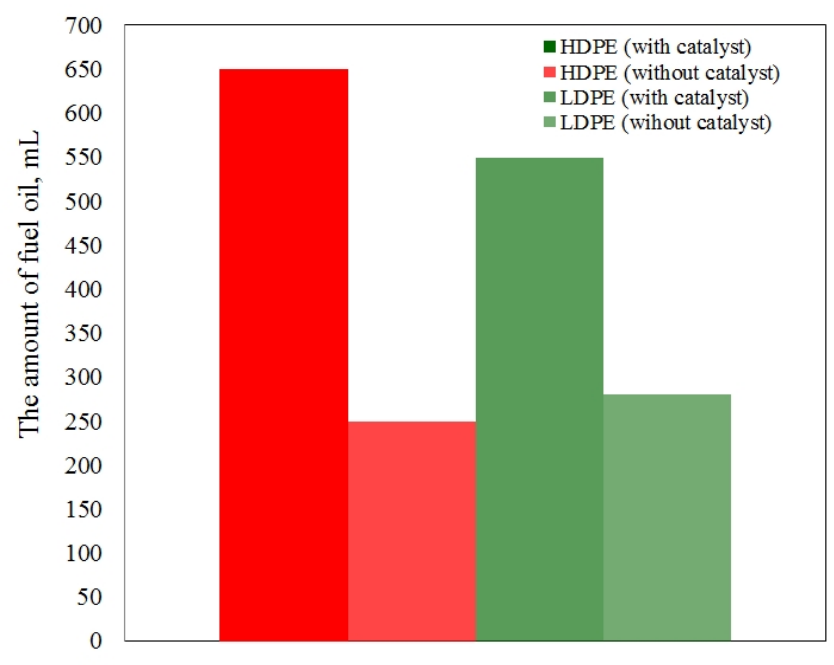

Fig. 3. Total fuel oil production

It was observed that at a temperature below $300{ }^{\circ} \mathrm{C}$ no fuel oil was produced, as the temperature is increased, there was an increment in a production of fuel oil. At a very high temperature of about $480{ }^{\circ} \mathrm{C}$, the experiment yielded the highest quantity of fuel oil product. The whole pyrolysis time of plastic waste in the reactor has great influence on the total fuel oil yield. It was observed that the longest time at maximum temperature gave the highest fuel oil yield. The total fuel oil yield was found for HDPE (with catalyst) and LDPE (with catalyst) plastic wastes pyrolysis were $65 \% \mathrm{vol} / \mathrm{w}$ and were $55 \% \mathrm{vol} / \mathrm{w}$, respectively as presented in Figure 2 . The increases in the weight of waste plastic feed have no effect on the obtained fuel oil yield. During thermal pyrolysis, it was obtained that at a temperature of about $480{ }^{\circ} \mathrm{C}$, the experiment yielded the highest quantity of liquid fuel oil as the total product. In this experiment, the amount of $1000 \mathrm{~g}$ HDPE and LDPE (with catalyst) used for pyrolysis feedstock yielded $650 \mathrm{~mL}$ and $550 \mathrm{~mL}$, respectively, as pointed in Figure 3. Desai and Galage, (2015) reported that 150 grams of LDPE plastic waste could form $100 \mathrm{ml}$ of fuel oil as benchmarks [9].

\subsection{Zeolite catalysts and fuel oil quality}

The above results were the comparison between the utilization of natural zeolite catalyst and non-catalysts in the second stage of HDPE and LDPE waste plastics pyrolysis. It is clear that the plastic wastes can be converted into fuel oil product which is in the range of physical parameters value as kerosene fuel. According to these results work, the highest fuel oil yield (65\%) was 
obtained through plastic wastes pyrolysis using natural zeolite catalyst. Yuliansyah et al. (2015) reported that pyrolysis of plastic waste in a semi-batch reactor at 400 ${ }^{\circ} \mathrm{C}$ using zeolite produced an oil yield as high as $41.9 \%$ $\mathrm{vol} / \mathrm{w}$, while pyrolysis without a catalyst only generated $11.4 \% \mathrm{vol} / \mathrm{w}$ [12]. This result is lower than this work, probably due to the lower reaction temperature and the larger size of plastic waste utilized. Higher temperatures of $480{ }^{\circ} \mathrm{C}$ and smaller plastic waste sizes will speed up the pyrolysis reaction. The high yield $(77-88 \%)$ of liquid product by using a semi-batch reactor at temperature range $400-550{ }^{\circ} \mathrm{C}$ was reported by several researchers [5], [9-12]. This means the yields of fuel oil production from pyrolysis of plastic waste can reach up to $80 \%$ or more, both using and without using a catalyst.

In this work, the presence of a natural zeolite catalyst may increase the pyrolysis reaction and improves the fuel oil yield. The use of natural zeolite catalyst was able to produce more fuel oil when compared with thermal degradation only (without catalyst) due to the length of the hydrocarbon chain become shorter and accelerate the reaction [6]. In this work, the advantage of using natural zeolite catalysts without activation and size of more than $10 \mathrm{~mm}$ is to put easily in the catalyst vessel, practically in preparation and there is no blockage in the tube by condensed gas of tar produced during the pyrolysis process.

Therefore, the natural zeolite is able to be used as catalyst although without any activation and has greatest potential to be developed into a commercialized process due to huge potential. Zeolite availability is spread in several regions in Indonesia. The generation of plastic wastes increases from time to time in Cimahi City. The fuel oil produced from plastic waste pyrolysis is suitable to be used as feedstock for value-added heating purposes in the rural and urban city [21]. The chemical composition of liquid fuel oil produced depends on plastic types, temperature operation time, type and amount of catalyst used and others various process conditions [10]. The main components of kerosene are paraffin, cycloalkanes (naphtha) and aromatic compounds, where paraffin is the highest composition. Syamsiro et al (2014) reported that the presence of the natural catalysts increased the yield of light oil $\left(\mathrm{C}_{5}-\mathrm{C}_{12}\right)$. According to its hydrocarbon chains of content, the experiment fuel oil resulted is in the range of gasoline and kerosene $[11,19,21]$. The physical properties of the fuel oil as described above tend to be close to kerosene oil. The quality of this liquid fuel oil was improved to remove the impurities by simple filtration.

Shah and Jan (2014) obtained the chemical composition of liquid fuel oil produced from MSW plastics mainly consists of aromatic hydrocarbons with some kinds of paraffin (alkanes: $\mathrm{C}_{n} \mathrm{H}_{2 n+2}$ ), olefins (alkenes: $\mathrm{C}_{\mathrm{n}} \mathrm{H}_{2 \mathrm{n}}$ ), and naphthenes (cycloalkanes) [23]. Rehan at al. (2016) found that pyrolytic oil both thermal and catalytic pyrolysis was dominated by aromatic hydrocarbons. Ethylbenzene $(21.2 \%)$, toluene $(25.6 \%)$ and benzo (b) triphenylene (1.6\%) and styrene (48.3\%) as the mayor compound were obtained from thermal pyrolysis. In catalytic pyrolysis with natural zeolite also produced the pyrolytic oil with styrene the major compound (60.8\%) with the remains compounds as methyl styrene $(10.7 \%)$, azulene $(4.8 \%), 1 \mathrm{H}$-indane $(2.5 \%)$ and ethylbenzene $(1.3 \%)$ [21].

In this work, the liquid fuel product was analyzed by using the results of FTIR spectrum measurements. The conventional kerosene oil FTIR spectrum results were used as a comparison. There are many peaks identified by the results of FTIR spectrum measurements of the liquid fuel oil products. The fuel oil products found the predominant presence of alkanes and alkenes group. The plastic waste pyrolytic fuel oils have several functional groups of alkanes $(\mathrm{CH})$, alkenes $(\mathrm{CH})(\mathrm{C}=\mathrm{C})$, aromatics $(\mathrm{C}=\mathrm{C})$, aldehydes, ketones, carboxylic acids and esters $(\mathrm{C}=\mathrm{O})$, alcoholic groups, phenol (hydrogen bond) $(\mathrm{OH})$, carboxylic acid group $(\mathrm{OH})$ and amine group $(\mathrm{CN})$. Likewise, the results of FTIR kerosene spectrum analyzed found in functional groups are alkanes $(\mathrm{CH})$, alkenes $(\mathrm{C}=\mathrm{C})$, aromatic $(\mathrm{C}=\mathrm{C})$, aldehydes, ketones, carboxylic acids and esters $(\mathrm{C}=\mathrm{O})$, alcohols, phenols hydrogen bonds $(\mathrm{OH})$, carboxylic acid $(\mathrm{OH})$ groups and amine $(\mathrm{NH})$ groups. These results are in agreement with other studies as described above that the fuel oil produced from these experiments is similar to conventional kerosene fuels.

\subsection{Future perspective}

The economic value was conducted by calculating the production cost and the price of the fuel oil produced per unit of $2000 \mathrm{~g}$ of plastic waste raw. Production cost is the consumption of LPG for the pyrolysis process of plastic waste excluding equipment investment cost. The operational cost of pyrolysis using LPG as a thermal source is about IDR 12,300/litre of fuel oil while the present market price of conventional kerosene oil is IDR 13,600/litre. The total amount of plastic waste collected from Cimahi city is 47 tonnes/day can be converted into the equivalent of 30,550 liters of kerosene fuel per day.

\section{Conclusions}

The fuel yield product obtained from pyrolysis by adding a natural zeolite catalyst was more than that without a catalyst. The total yield of $650 \mathrm{~mL}(65 \% \mathrm{vol} / \mathrm{w})$ and $550 \mathrm{~mL}(55 \% \mathrm{vol} / \mathrm{w})$ were found from pyrolysis of the amount of $1000 \mathrm{~g}$ HDPE plastics waste and LDPE plastics waste with natural zeolite catalyst at a maximum temperature of $580{ }^{\circ} \mathrm{C}$, respectively. The physical properties of this fuel oil obtained were higher than diesel and in the range with kerosene. The density of fuel oil product from $0.700 \mathrm{~kg} / \mathrm{m}^{3}$ to $0.710 \mathrm{~kg} / \mathrm{m}^{3}$ and the fuel oil kinematic viscosity in the range of $1.07 \mathrm{cSt}$ to $1.14 \mathrm{cSt}$ were close to density and kinematic viscosity of kerosene $\left(0.780 \mathrm{~kg} / \mathrm{m}^{3}-0.810 \mathrm{~kg} / \mathrm{m}^{3}\right.$ and $\left.0.377 \mathrm{cSt}-4.123 \mathrm{cSt}\right)$. The heating value of fuel oil from the pyrolytic plastic waste of $37.99 \mathrm{MJ} / \mathrm{kg}$ was also so similar to that of kerosene. The results of FTIR pyrolytic fuel oil spectrum contained the functional groups were similar to that of conventional kerosene fuels within the agreement with formerly research studies. Natural zeolite catalysts should be used due to high fuel yield $(\%)$, good degradation 
efficiency and widely available in nature. Therefore, the fuel oil from pyrolysis of plastic wastes can be considered as an alternative energy to use as fuel for cookstoves as an LPG/kerosene substitute for the household in both urban or rural area. However, further studies should be undertaken if this fuel oil is used as kerosene substitute. Large amounts of plastic waste in Cimahi City should be trimmed down by pyrolysis. Pyrolysis is one among several promising thermal treatments in handling the plastic waste problem. The plastic waste of about 47 tonnes/ day in Cimahi City can be converted into fuel oil that similar to kerosene of 30,550 liters/day with an economic value of IDR 415,480,000/day. Considering the advantages of implementing this technology, it is important for the further study in giving an initial vision of possible low-carbon society (LCS) scenario in Indonesia.

\section{Further work}

Since the experiment results are technically interesting and are able to overcome the problem of plastic waste and have value-added economically in Cimahi city, further work is directed to the development of pyrolysis reactors with heating systems using biomass waste as the reactor heat source. The studies of the fuel oil produced characterization, the design of pressurized oil stoves and the feasibility study of its economics will be undertaken for significant improvement and full substitution of kerosene/LPG. This research is expected to improve the reliability of reactors and pyrolysis processes and can be applied to real commercial applications in urban or rural communities.

\section{Acknowledgments}

The authors would like to thank the Ministry of Research, Technology and Higher Education (DRPMRISTEKDIKTI), Indonesia for financial support for carrying out this research through the PTUPT-scheme. The authors would also like to express thanks to the local government of Cimahi City who has participated in testing and surveys for this study. We also wish to thank our students for their assistance in conducting this experiment.

\section{References}

1. The government of Cimahi City. Data of Cimahi Municipal Waste Management, Local Government, Cimahi, (2015).

2. M.I. Jahirul, M.G. Rasul, A. A. Chowdhury, N. Ashwath, Energies, 5( 2012).

3. T. Fisher, M. Hajaligol, B. Waymack, D. Kellogg, J. Analytical App. Pyrolysis, 6, 2 (2002).

4. A. Dhaundiyal, J. Gangwar, Acta Universitatis Sapientiae Agr. Env, 7 (2015).

5. P. Das, P. Tiwari, Resources, Consv. \& Recyc., 128 (2018).

6. D.C. Tiwari, E. Ahmad, K. Singh, Int.l J. of Chem. Res., 1, 2 (2009).

7. A. Singhabhandhu, T. Tezuka, Energy, 35(2010).

8. S.M. Al-Salem, P. Lettieri, J. Baeyens, Waste Management, 29 (2009).

9. S.B. Desai, C. K. Galage, Int. J. Eng. Res. G. Sci. 3, 1(2015).

10. R. Miandad, M. Barakat, M. Rehan, A. Aburiazaiza, I. Ismail, A. Raini, Waste Management, 69 (2017).

11. M. Syamsiro, S. Cheng, H. Saptohadi, S. Cheng, N.N. Pratama, W. Trisunaryati, W. Hu, Waste Tech. 2, 2 (2014).

12. A.T. Yuliansyah, A. Prasetya, M. A. A. Ramadhan, R. Laksono, Int. J. Tech., 7 (2015).

13. Suhartono, Suharto, A. E. Ahyati, IOP: Earth and Envi. Sci., 105 (2018).

14. A. Demirbas, Fuel, 87, 8-9 (2008).

15. Suhartono, T.Ai Putri, L. Fauziah, Int. J. Adv. Sci. Eng.Inf. Tech. 7, 4 (2017).

16. A Demirbaş, Engy. Conv. Mng., 41, 15, (2000).

17. N.U. Hasan, M.M Rahman, R.I. Rahat, The 4th Int. Conf. Adv. Elect. Eng. (ICAEE), Dhaka, (2017).

18. Jr. H. Curl and K. O'Donnell, Colorado, USA: National Oceanic and Atm. Adm., (1997).

19. B.P. More, M.K. Malve, R.B. Toche, D.B. Shinde, Int. J. Phar. Bio. Sci., 2, 4 (2012).

20. J. Walendziewski, Fuel, 81( 2002).

21. M. Rehan, M. Miandat, M. Barakat, M. Ismail, T Alneelbi, J. Gardy. Int. J. Biodet. Biodeg., 119, (2017).

22. K. Miteva1, S. Aleksovski, G.B. Gaceva, Zastita Materijala, 57, 4, (2016).

23. J.Shah, M.R. Jan, Adnan, Korean J. Chem. Eng. 31, 8, (2014). 